\title{
On the Formal Theory of Inspection and Evaluation in Product Markets
}

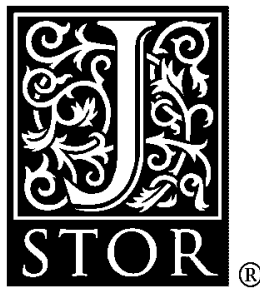

Louis L. Wilde

Econometrica, Vol. 48, No. 5. (Jul., 1980), pp. 1265-1279.

Stable URL:

http://links.jstor.org/sici?sici=0012-9682\%28198007\%2948\%3A5\%3C1265\%3AOTFTOI\%3E2.0.CO\%3B2-K

Econometrica is currently published by The Econometric Society.

Your use of the JSTOR archive indicates your acceptance of JSTOR's Terms and Conditions of Use, available at

http://www.jstor.org/about/terms.html. JSTOR's Terms and Conditions of Use provides, in part, that unless you have obtained prior permission, you may not download an entire issue of a journal or multiple copies of articles, and you may use content in the JSTOR archive only for your personal, non-commercial use.

Please contact the publisher regarding any further use of this work. Publisher contact information may be obtained at http://www.jstor.org/journals/econosoc.html.

Each copy of any part of a JSTOR transmission must contain the same copyright notice that appears on the screen or printed page of such transmission.

The JSTOR Archive is a trusted digital repository providing for long-term preservation and access to leading academic journals and scholarly literature from around the world. The Archive is supported by libraries, scholarly societies, publishers, and foundations. It is an initiative of JSTOR, a not-for-profit organization with a mission to help the scholarly community take advantage of advances in technology. For more information regarding JSTOR, please contact support@jstor.org. 


\title{
ON THE FORMAL THEORY OF INSPECTION AND EVALUATION IN PRODUCT MARKETS
}

\author{
By LOUIS L. WILDE ${ }^{1}$
}

\section{INTRODUCTION}

WHILE THE OVERALL IMPORTANCE of drawing a distinction between information concerning characteristics of goods which are directly observable and information concerning characteristics of goods which cannot be observed without actual "consumption" in some appropriate sense has just begun to be realized, labor economists have implicitly been making use of the distinction for some time. For example, researchers studying labor mobility in the early fifties such as Reynolds [9] emphasized that high job turnover by young workers could be explained in part as a kind of job-shopping. More recently, Pencavel [7] has used the notion that all characteristics of jobs cannot be observed by simply sampling firms as the basis for an equilibrium model of job quits, and Wilde [10] has explored optimal search strategies when jobs are characterized by multiple characteristics, some of which are directly observable and others of which cannot be observed without actually taking the job.

Besides these applications to the quit-rate, the distinction between different kinds of information can be used to analyze a number of economic phenomenon, both in the labor market and in other markets characterized by imperfect and costly information. Stiglitz [8] has applied it to the economic theory of screening and education, and Nelson [6] has used it in a unique approach to consumer behavior in product markets.

Nelson partitions goods into two classes: search goods and experience goods. The distinction between the two classes is drawn in terms of the consumer's preferred mode of evaluating the potential stream of utility yielded by purchasing a good. For search goods the evaluation occurs prior to purchase; that is, a decision to purchase the good is based only on price (and other directly observable characteristics), not on any unobservable qualitative features of the product. Experience goods are those for which the primary information process used to evaluate the potential utility of a purchase is actual consumption of the good.

This paper is motivated in part by Nelson's work but, unlike it, the focus is directly on individual characteristics as opposed to total packages of characteristics. That is, two classes of characteristics are defined. Search characteristics are those which can be observed without actually consuming the good, and experience characteristics are those which cannot be observed without consumption. Investment in information about search characteristics will be called inspection, as suggested by Hirshleifer [1], and investment in information about experience characteristics will be called evaluation.

To see the difference between this approach and Nelson's, suppose a good is described by a vector of characteristics $\left(x_{1}, x_{2}, \ldots, x_{n}\right)$. Nelson implicitly assumes

\footnotetext{
${ }^{1}$ I would like to thank Robert Forsythe and Bill Rogerson for extremely helpful discussions of this material. An anonymous referee also provided useful comments on an earlier draft.
} 
each value $x_{i}$ is potentially observable prior to purchase and that the consumer must choose between paying a "search cost" and observing all $x_{i}$ prior to purchase or paying the purchase price and observing all $x_{i}$ by direct consumption. This strong dichotomy leads to some contradictions though. For an example consider experience goods. Since an experience good is evaluated by direct consumption, the good must actually be purchased. But by definition, price cannot effect the decision concerning which good to buy. Thus for experience goods Nelson assumes "consumers either sample at random from among all brands or from those brands in the price range the consumer deems appropriate for himself." This implicitly requires the further assumption that the consumer either ignores price altogether or has perfect information about price and is imperfectly informed only about qualitative characteristics of the good.

There are several ways to avoid these logical difficulties. In keeping with the spirit of Nelson's definitions, one can assume each characteristic $x_{i}$ is potentially observable by paying a characteristic-specific search cost, $c_{i}$. The consumer draws goods at random and observes at least price. Subsequently he or she can either buy the good, observe more characteristics prior to purchase, or reject the good and draw a new observation. This is essentially the kind of problem analyzed by MacQueen [4]. Nelson's search goods and experience goods are special cases in this model; search goods are those for which all characteristics $\left(x_{1}, x_{2}, \ldots, x_{n}\right)$ are necessarily observed prior to purchase (at cost equal to the sum of all $c_{i}, i=$ $1, \ldots, n)$, and experience goods are those for which only price is observed prior to purchase (and, furthermore, all prices are acceptable).

The point of departure of this paper is to consider goods for which a subset of the characteristic-specific search costs are infinite. In particular, it will be assumed that goods can be described by two characteristics, price and quality, with price being directly observable but quality being observable only by consumption of the good. A crucial difference between the model developed in this paper and MacQueen's model is that the former allows for repeat purchases as part of an optimal search strategy while the latter does not. In the absence of repeat purchases it is meaningless to talk about experience goods.

The next section of this paper defines the search environment for this problem. Section 3 then sets up the dynamic programming problem faced by the consumer, derives the relevant functional equation, and establishes conditions under which there is a unique reservation price. Section 4 develops some specific properties of the optimal policy for the general case. In particular, it is shown that one of the following situations applies for any given level of search costs; (i) all prices and all qualities are acceptable; (ii) all prices are acceptable but some quality levels will be rejected; acceptable quality is a function of observed price; (iii) some prices are rejected as well as some qualicy levels; acceptable quality remains a function of price; or (iv) only the lowest price is acceptable; some quality levels are rejected. Corollary to this categorization is the observation that there are no search goods in the sense that Nelson uses that term (if price matters then quality must matter for some prices) and experience goods exist only when search costs (for observing prices) are zero. Section 5 considers a special model which allows one to derive comparative statics with respect to changes in the lifetime of the good. It is argued 
there that a "price-compensated" increase in durability lowers both the reservation price and reservation qualities, causing a shift away from evaluation and towards inspection. A final section discusses and summarizes the results obtained.

\section{BASIC ASSUMPTIONS OF THE MODEL}

The problem analyzed in this paper is set in the product market. Goods vary with respect to both price and some nonprice characteristic, quality. Consumers are imperfectly informed about the specific price-quality pairs offered by individual firms. For a given cost they can, however, draw samples from the market distribution and observe price prior to consumption. Formal definitions and assumptions regarding this search environment follow.

Each good is described by a pair $(p, q)$ where $p$ is price and $q$ is quality. The net utility to the consumer obtained by purchasing a good at price $p$ with quality $q$ is $U(p, q)$. Each good has a lifetime of $s$ periods.

Assumption 1: $U$ is differentiable and bounded on $\boldsymbol{R}_{+} \times \boldsymbol{R}_{+}$with $\partial U(p, q) /$ $\partial p<0$ and $\partial U(p, q) / \partial q>0$.

Let $\phi(p, q)$ be the joint probability density function defining the market distribution of $P$ and $Q$ and $g(q \mid p)$ be the conditional probability density function of $Q$ given $P=p$.

Assumption 2: $\phi(p, q)>0$ for all $(p, q) \in[0, \bar{p}] \times R_{+}$where $\bar{p}>0 .^{3}$

The cost of drawing an observation at random from $\phi$ and observing price is $c$. The cost of returning to a specific firm and repurchasing a given good is $r$. Both $c$ and $r$ are measured in the same units as $U$. To keep the search problem nontrivial, assume the following:

Assumption 3: $E[U(P, Q)]>c \geqslant r \geqslant 0$.

The objective of the consumer is to maximize his or her discounted sum of utility of consumption, net of search costs. As many observations as are desired may be taken from $\phi$ at the beginning of each period but at most one unit of the good is demanded per period. ${ }^{4}$ Sampling is without recall, the horizon is infinite, and the discount rate is $\beta, 0<\beta<1$.

${ }^{2}$ A "price-compensated" increase in durability is one in which the per-period net utility associated with a particular price-quality combination is independent of the durability of the good. See Section 5 and footnote 10 .

${ }^{3}$ It turns out to be convenient to assume $\phi(p, q)>0$ on $[0, \bar{p}] \times R_{+}$and to assume $\bar{p}$ is finite. Neither assumption is crucial.

${ }^{4}$ There are two kinds of "search" in this model. Inspection consists of drawing observations from $\phi$ and observing $P$. Evaluation is the subsequent purchase of a good and the observation of $Q$. Inspection is assumed to be a timeless activity, the only cost is the direct sampling cost, $c$. Evaluation is assumed to take time. This means that two types of costs are associated with evaluation; the opportunity cost of consuming at a low quality level and the postponement into the future of the possibility of rectifying the purchase of a poor quality good. Inspection is assumed to be a timeless activity in order to isolate the latter. 
The consumer therefore faces the following problem. He or she knows $\phi$. By paying $c$ an observation can be drawn from this distribution, say $\left(p_{0}, q_{0}\right)$. The consumer observes only $p_{0}$; information regarding $q_{0}$ is provided by the conditional distribution of $Q$ given $p_{0}$. Based on this distribution the consumer must decide whether or not to purchase the good. In the absence of any constraints on $\phi$, there is no definite relationship between price and the expected long-run utility from purchasing the good. For example, if there is a strong positive correlation between price and quality then the consumer might reject low prices and search out higher ones. If this positive correlation is weak enough (or, in general, nonexistent) then low prices will be preferred to high prices. Another possibility is disjoint intervals of acceptable prices separated by ranges of unacceptable prices. For the sake of discussion, assume that $P$ and $Q$ are positively correlated, but that low prices are preferred to high systematically. In this case, if $p_{0}$ (the observed price) is low enough, then the consumer may decide to purchase the good. Otherwise it is rejected and another observation from $\phi$ is drawn. If the good is purchased, the consumer receives $U\left(p_{0}, q_{0}\right)$ over the $s$ period lifetime of the good. At the end of $s$ periods the consumer can either pay $r$ and repurchase $\left(p_{0}, q_{0}\right)$, or another sample can be drawn from $\phi$ at cost $c{ }^{5}$ In general there will be a positive probability of the consumer not being satisfied with $q_{0}$ (after purchase) since there will be ranges of price for which the conditional expected utility of consumption is high enough to warrant purchase even though there is a possibility of being disappointed. Given a little more structure on $\phi$ it is possible to show that under an optimal policy the initial purchase decision is based on some critical value of $P$, and the decision whether or not to repurchase a particular price-quality pair is based on a critical value of $Q$. That is, the optimal strategy is characterized by a pair $\left(\xi, q^{*}(p)\right)$ where $\xi$ is a reservation price level and $q^{*}(p)$ is a reservation quality level.

\section{THE OPTIMAL POLICY: EXISTENCE AND UNIQUENESS OF}

\section{A RESERVATION PRICE}

Let $v(p)$ be the expected discounted sum of utility (net of search costs) generated by an optimal policy when an observation of $p$ has just been drawn. Define $V$ as the expected value of $v(p)$ taken with respect to the marginal distribution of $p$; that is,

$$
V=\int_{0}^{\bar{p}} v(p) f(p) d p
$$

where $f(p)$ is defined by

$$
f(p)=\int_{0}^{\infty} \phi(p, q) d q
$$

\footnotetext{
${ }^{5}$ It is implicit that price and quality combinations are such that it never pays to throw away a poor quality good and initiate new inspection prior to the end of the $s$ period lifetime of the good. Also, since inspection is timeless, it never pays to draw new samples from $\phi$ (in the event that $\left(p_{0}, q_{0}\right)$ is a poor price-quality pair) until the end of $s$ periods.
} 
Since the consumer follows an optimal strategy, $v(p)$ is defined by

$$
v(p)=-c+\max \{V, B(p)\},
$$

where $B(p)$ is the expected discounted sum of utility generated by an optimal policy conditional on buying the good priced at $p$. The logic of (3) is that the consumer must pay $c$ to observe $p$. If $p$ is an acceptable price, then $v(p)=$ $-c+B(p)$. If $p$ is not acceptable then a new draw is taken from $\phi$ and the expected utility of searching, $V$, is received; $v(p)=-c+V$.

Next consider $B(p)$. If the consumer purchases the good after observing $p$, then the expected utility of consumption (net of price) during the next $s$ periods is

$$
E[U(p, Q)]=\int_{0}^{\infty} U(p, q) g(q \mid p) d q
$$

where $g(\cdot \mid p)$ is the conditional probability density function of $Q$ given $P=p$. At the end of $s$ periods the consumer can either repurchase the good or draw a new sample from $\phi$. The decision is clearly based on the observed value of $Q$. If the consumer repurchases the good, $[U(p, q)-r]$ is received every $s$ periods (if a repurchase is made once after observing $Q$, it will always pay to repurchase). If the consumer samples again $V$ is received. Therefore, define $q^{*}(p)$ by

$$
\begin{aligned}
V & =\sum_{i=0}^{\infty} \beta^{i s}\left[U\left(p, q^{*}(p)\right)-r\right] \\
& =\left(1-\beta^{s}\right)^{-1}\left[U\left(p, q^{*}(p)\right)-r\right] .
\end{aligned}
$$

Thus $q^{*}(p)$ is that quality level which makes the consumer indifferent between repurchasing a good with characteristics $\left(p, q^{*}(p)\right)$ and sampling again. Note that if (5) has an interior solution then Assumption 1 implies $q^{*}(p)$ is unique. But there may be values of $P$ such that $V\left(1-\beta^{s}\right)<[U(p, 0)-r]$ or it may be that $V(1-$ $\left.\beta^{s}\right)>\lim _{q \rightarrow \infty}[U(p, q)-r]$. In the former case define $q^{*}(p)=0$ and in the latter let $q^{*}(p)=\infty$. Then when $q^{*}(p)=\infty$ it must be that

$$
V \geqslant\left(1-\beta^{s}\right)^{-1}\left[\lim _{q \rightarrow \infty} U(p, q)-r\right]
$$

and when $q^{*}(p)=0$ it must be that

$$
V \leqslant\left(1-\beta^{s}\right)^{-1}[U(p, 0)-r] .
$$

Since $\partial U(p, q) / \partial q>0$, we have that $q<q^{*}(p)$ implies the consumer resamples, and $q \geqslant q^{*}(p)$ implies the consumer repurchases. Hence the probability that the consumer samples again after $s$ periods is $G\left(q^{*}(p) \mid p\right)$, and the probability the consumer repurchases the original good is $\left[1-G\left(q^{*}(p) \mid p\right)\right]$, where $G(\cdot \mid p)$ is 
the cumulative density function associated with $g(\cdot \mid p)$. Therefore $B(p)$ is defined by

$$
\begin{aligned}
B(p)= & E[U(p, Q)]+\beta^{s}\left\{G\left(q^{*}(p) \mid p\right) V\right. \\
& \left.+\left(1-\beta^{s}\right)^{-1} \int_{q^{*}(p)}^{\infty}[U(p, q)-r] g(q \mid p) d q\right\} .
\end{aligned}
$$

Using (8) in equation (3), the basic functional equation associated with the consumer's problem can be written as

$$
\begin{aligned}
v(p)= & -c+\max \{V, E[U(p, Q)] \\
& \left.+\beta^{s}\left\{G\left(q^{*}(p) \mid p\right) V+\left(1-\beta^{s}\right)^{-1} \int_{q^{*}(p)}^{\infty}[U(p, q)-r] g(q \mid p) d q\right\}\right\} .
\end{aligned}
$$

Before analyzing (9) in more detail, one would normally show that it has a unique solution. Establishing existence is trivial. Uniqueness and continuity are more difficult. Since the focus here is not on these technical details, though, they will simply be assumed to hold.

Assumption 4: There exists a unique, continuous, bounded solution to the functional equation (9). ${ }^{6}$

In the present setting, this assumption is not as strong as it might seem. It only establishes that for any observed price there is a determinate solution to accepting or rejecting the associated good and that $V$ is unique and can thus be treated as a constant. It does not imply the reservation price is unique. ${ }^{7}$

There are two natural sets of sufficient conditions for the reservation price to be unique in this model. One is $B(0) \geqslant V$ and $d B(p) / d p<0$ for all $p$ in $[0, \bar{p}]$. The other is $B(0) \leqslant V$ and $d B(p) / d p>0$ for all $p$ in $[0, \bar{p}]$. In the former case low prices are acceptable and high prices are not, while in the latter case the opposite is true. Both cases are consistent with the notion that higher quality is associated with higher price. Here this translates as $\partial G(q \mid p) / \partial p<0$; the probability that quality is less than some given $q$ falls as price rises, or higher price implies that "on average" quality is higher. But it is the combination of price and quality which is important; the distribution of $U(p, q)$ is what matters to the consumer.

Let $\hat{q}(w, p)$ be the value of $q$ which sets $U(p, \hat{q})=w$. Then $\partial \hat{q} / \partial p=-U_{1} / U_{2}>$ 0 . Define $\Psi(w \mid p)$ as the cumulative density function of $w=U(p, q)$ conditional

\footnotetext{
${ }^{6}$ For a proof of this result when inspection is not timeless, see Wilde [10]. A general proof in the timeless case is provided by MacQueen and Miller [5].

${ }^{7}$ It would be straightforward to generalize this model to one in which both very low prices and very high prices are rejected. The analysis would be more complicated but the qualitative results would be the same. The primary difference would be that instead of presenting these results in terms of the reservation price, they would be presented in terms of the set of acceptable prices (which would have both upper and lower bounds).
} 
on $P=p$. Then $\Psi(w \mid p)=G(\hat{q}(w, p) \mid p)$, and

$$
\frac{\partial \Psi(w \mid p)}{\partial p}=\frac{\partial G(\hat{q} \mid p)}{\partial p}+g(\hat{q} \mid p) \frac{\partial \hat{q}}{\partial p} .
$$

With $\partial G(\hat{q} \mid p) / \partial p<0$ it is not possible to sign $\partial \Psi(w \mid p) / \partial p$ since both $g(\hat{q} \mid p)$ and $\partial \hat{q} / \partial p$ are positive. In general one would expect $\partial \Psi(w \mid p) / \partial p>0$. That is, a higher price should denote lower expected utility for any good within a generic class. This is the case, for example, when price and quality are independent. In the absence of an equilibrium model which generates $\phi$ endogenously, or of a more precise specification of what "quality" means, independence may be a reasonable working assumption, especially since the crucial property is not $\partial G(q \mid p) / \partial p<0$ but rather $\partial \Psi(w \mid p) / \partial p>0$. For now we simply posit the following assumption.

Assumption 5: $\partial \Psi(w \mid p) / \partial p>0$ for all $w \geqslant U(\bar{p}, 0)$ and $p \in[0, \bar{p}]$.

Lemma 1: Assume Assumptions 1 through 5 hold. Then $d B(p) / d p<0$ for all $p \in[0, \bar{p}]$.

Proof: From (8), integrating by parts, using $\Psi(w \mid p)$, and defining $\bar{w}(p)=$ $U(p, 0)$ and $\overline{\bar{w}}(p)=\lim _{q \rightarrow \infty} U(p, q), B(p)$ can be written as

$$
\begin{aligned}
B(p)= & \left(1-\beta^{s}\right)^{-1} \overline{\bar{w}}(p)-\int_{\bar{w}(p)}^{\bar{w}(p)} \Psi(w \mid p) d w \\
& -\beta^{s}\left(1-\beta^{s}\right)^{-1}\left[r+\int_{V\left(1-\beta^{s}\right)+r}^{\bar{w}(p)} \Psi(w \mid p) d w\right] .
\end{aligned}
$$

Differentiating (11) with respect to $p$,

$$
\frac{d B(p)}{d p}=-\int_{\bar{w}(p)}^{\bar{w}(p)} \frac{\partial \Psi(w \mid p)}{\partial p} d w-\beta^{s}\left(1-\beta^{s}\right)^{-1} \int_{V\left(1-\beta^{s}\right)+r}^{\bar{w}(p)} \frac{\partial \Psi(w \mid p)}{\partial p} d w .
$$

Thus, $\partial \Psi(w \mid p) / \partial p>0$ implies $d B(p) / d p<0$.

Q.E.D.

Lemma 2: Assume Assumptions 1 through 5 hold. Then $(i) B(0)>V$ iff $c>0$ and (ii) $B(0)=V$ iff $c=0$.

Proof: (i) Assume $c>0$ and $B(0) \leqslant V$. Then, since $d B(p) / d p<0$ for all $p \in[0, \bar{p}], B(p) \leqslant V$ for all $p \in[0, \bar{p}]$. Hence $\max \{V, B(p)\}=V$ and $v(p)=$ $-c+V$ for all $p \in[0, \bar{p}]$. Integrating with respect to $p$ then gives $V=-c+V$, or $c=0$ which is a contradiction. Hence $c>0$ implies $B(0)>V$.

Next let $B(0)>V$. Then either $B(p)>V$ for all $p \in[0, \bar{p}]$ or there exists $\xi \in(0, \bar{p}]$ such that $B(\xi)=V$. In the former case $\max \{V, B(p)\}=B(p)$ for all $p \in[0, \bar{p}]$ and hence $c=E[B(P)]-V>0$. In the latter case

$$
c=\int_{0}^{\xi}[B(p)-V] f(p) d p
$$


where $f$ is the marginal probability density function of $P$. Since $B(p)>V$ for all $p \in[0, \xi)$ and $\xi>0$, this again implies $c>0$. Hence $B(0)>V$ implies $c>0$.

(ii) From part (i) we know $c=0$ implies $B(0) \leqslant V$; but $B(0)<V$ contradicts the assumption that $E[U(P, Q)]>c$. Hence $c=0$ implies $B(0)=V$. That $B(0)=V$ implies $c=0$ follows as above.

Q.E.D.

Given Lemmas 1 and 2, the following theorem can be stated without proof.

TheOREM 1: Assume Assumptions 1 through 5 hold. Then either $B(p)>V$ for all $p \in[0, \bar{p}]$ or there exists a unique $\xi \in[0, \bar{p}]$ such that $B(\xi)=V$. Moreover $\xi=0$ if and only if $c=0$.

Since $\xi$ is a reservation price, the optimal strategy for the consumer in this problem is analogous to simple search models; the consumer draws observations from $\phi$ (effectively draws of $p$ from $f(p)$ ) until one less than or equal to $\xi$ is found. In the simple problem the consumer would buy the homogeneous good at price $p$ in all subsequent periods. Here, because goods are heterogeneous with respect to quality, the consumer buys the good just once, until quality can be evaluated. If $q$ is less than $q^{*}(p)$, then the consumer draws again from $\phi$ but $\xi$ does not change.

\section{PROPERTIES OF THE OPTIMAL POLICY}

The optimal policy of the consumer is summarized in two variables and two equations (assuming $\xi<\bar{p}$ ):

$$
\begin{aligned}
& V=B(\xi), \\
& c=\int_{0}^{\xi}[B(p)-B(\xi)] f(p) d p .
\end{aligned}
$$

With some manipulation of these two equations, comparative statics are reasonably straightforward. In particular, $d \xi / d c>0$; as search costs rise so does the reservation price. Moreover, $d q^{*}(p) / d c<0$ so that higher direct search costs implies less evaluation. ${ }^{8}$ Neither of these results is surprising though. More interesting results concern the relationship of acceptable prices to acceptable quality levels.

THEOREM 2: $\xi \in[0, \bar{p})$ implies $q^{*}(\xi)>0$.

\footnotetext{
${ }^{8}$ This is a conditional reduction in evaluation. The ex ante expected probability of not repurchasing a good is

$$
\tau \equiv F(\xi) \int_{0}^{\xi}\left[1-G\left(q^{*}(p) \mid p\right)\right] f(p) d p .
$$
}

Since $d \xi / d c>0$ and $d q^{*}(p) / d c<0$, it is not possible to sign $d \tau / d c$. 
Proof: With $\xi \in[0, \bar{p})$, it must be that $B(\xi)=V$. The claim is that $q^{*}(\xi)>0$. Assume the opposite. Then by definition

$$
V \leqslant\left(1-\beta^{s}\right)[U(\xi, 0)-r] .
$$

By assumption, though, $V$ is given as

$$
\begin{aligned}
V= & E[U(\xi, Q)]+\beta^{s}\left\{V G\left(q^{*}(\xi) \mid \xi\right)\right. \\
& \left.+\left(1-\beta^{s}\right)^{-1} \int_{q *(\xi)}^{\infty}[U(\xi, q)-r] g(q \mid \xi) d q\right\} .
\end{aligned}
$$

Using $q^{*}(\xi)=0$, this can be written as

$$
V=\left(1-\beta^{s}\right)^{-1}\left\{E[U(\xi, Q)]-\beta^{s} r\right\} .
$$

From (15) we have, then, that $q^{*}(\xi)=0$ implies

$$
U(\xi, 0) \geqslant E[U(\xi, Q)]+\left(1-\beta^{s}\right) r .
$$

Clearly there is a contradiction here (even if $r=0$ ) since 0 is the minimum quality associated with any price.

Q.E.D.

Theorem 2 says that quality is never irrelevant when price matters. That is, if it pays to set a reservation price strictly less than $\bar{p}$, then at that reservation price (and in a neighborhood of it) it pays to reject some quality levels. The theorem does not imply $q^{*}(p)>0$ for all $p \leqslant \xi$. For example, at $p=0$ it may be optimal to accept all quality levels rather than resample. In one sense Theorem 2 is very strong: it implies there are no "search" goods regardless of the level of search costs. In fact, if $c=0$, then $\xi=0$, but $q^{*}(0)$ is not necessarily infinite. The following corollary demonstrates that if $r \rightarrow 0$ as $c \rightarrow 0$ (certainly the case when $c \geqslant r$ for all $c$ and $r$ ), then $q^{*}(0)$ is finite.

CoRollary 1: Let $c=0=r$. Then $0<q^{*}(0)=q^{*}(\xi)<\infty$.

Proof: When $c=0$, then $B(0)=V$. Hence 0 is the optimal price and $g(\cdot \mid 0)$ is the optimal distribution from which to draw quality samples. The proof of Theorem 2 then applies with $\xi=0$, yielding $q^{*}(\xi)=q^{*}(0)>0$. To see that $q^{*}(0)<\infty$ again assume the opposite. Then by definition (and given $r=0$ ), $V \geqslant$ $\left(1-\beta^{s}\right)^{-1}\left[\lim _{q \rightarrow \infty} U(0, q)\right]$. But $V=B(0)$ implies $V=E[U(0, Q)]+\beta^{s} V$. Hence $E[U(0, Q)] \geqslant \lim _{q \rightarrow \infty} U(0, q)$, which is clearly a contradiction when $\partial U / \partial q>0$. Thus, $q^{*}(0)$ is finite.

Q.E.D.

If $r$ remained positive as $c \rightarrow 0$, then it might pay to always resample since repurchase involves the cost $r$. But this is a silly assumption when $c=0$. Corollary 1 describes the case analyzed by Nelson [6]; the only relevant "search costs" are the opportunity costs of consuming at a low quality level. Hence when $c=0=r$ goods are truly experience goods in the sense that Nelson uses that term, but to get 
to this case it is not only necessary that the cost of direct sampling of quality be high (in this model it is infinite), it is also necessary that the cost of observing price be zero. ${ }^{9}$

Corollary 2: If $B(\bar{p})=V$, then $q^{*}(\xi)=q^{*}(\bar{p})>0$.

Proof: The proof of Theorem 2 applies directly.

Q.E.D.

In effect Corollary 2 demonstrates that when direct search costs are high the good may be an "experience" good; the consumer ignores price and samples until a satisfactory quality level is found. The quality level which is acceptable is not independent of price, though. That is, if $\xi=\bar{p}$ then for some prices $q^{*}(p)$ must exceed 0 and, in any case, is still sensitive to the observed price-there is no "reservation" quality independent of price.

To summarize, then, consider first $c=0=r$. In this case $\xi=0$ (the lowest price) and only quality matters. The consumer sets a reservation quality $q^{*}=q^{*}(0)=$ $q^{*}(\xi)$ and samples from $g(\cdot \mid 0)$ until a quality level which beats $q^{*}$ is found. Next let $c \geqslant r>0$. Assume $0<\xi<\bar{p}$. In this case it may or may not be true that $q^{*}(p)>0$ for any given acceptable price $(p \leqslant \xi)$; for some prices all quality levels may be acceptable. But $q^{*}(\xi)>0$; at the margin it always pays to allow for the possibility of rejecting some quality levels. As $c$ rises, so does $\xi$. Eventually $\xi=\bar{p}$, the maximum price, and all prices are acceptable. In this case goods are experience goods in the sense that any price is acceptable, but acceptable quality levels are still sensitive to the observed price; that is, $q^{*}(p)$ is sensitive to the observed price, $p$.

It would next be desirable to get comparative statics with respect to $s$. But as the model stands there is no way to let $s$ change without changing the net utility per period obtained from a given purchase. One way around this is to let $U(p, q)$ be linear in $p$ and adjust prices to keep per period utility constant when $s$ changes. This is taken up in the next section.

\section{DURABILITY: CHANGES IN $S$}

In order to make comparisons between goods with different durabilities, it is necessary to control for the flow of utility obtained by paying particular prices. Let the net utility of purchase be linear in price and assume

$$
U(p, q)=\sum_{i=1}^{s} \beta^{i-1}[u(q)-p]=b(s)[u(q)-p],
$$

where $b(s)=\Sigma_{i=1}^{s} \beta^{i-1}$. At any given price-quality pair, the difference in the purchase of a good with duration $s$ and one with duration $s+1$ is $\beta^{s}[u(q)-p]$.

\footnotetext{
${ }^{9}$ Kohn and Shavell [2] have also considered this case. But in their model, as in Nelson's, the cost of search is either defined to include the foregone opportunity cost of consuming at a low quality level or it is not-there is no possibility for the consumer to decide.
} 
Hence in the absence of repurchase costs the total discounted "cost" of maintaining a per-period flow of utility $u\left(q_{0}\right)$ when the pair $\left(p_{0}, q_{0}\right)$ has been drawn from $\phi$ is independent of the durability of the good. This will be referred to as a "price-compensated" increase in durability. ${ }^{10}$

This section deals with the effects of changes in durability so all relevant functions and variables will be indexed by $s$. Thus by definition

$$
v_{s}(p)=-c+\max \left\{B_{s}(p), V_{s}\right\}
$$

and using (20),

$$
\begin{aligned}
B_{s}(p)= & b(s) E[u(Q)-p \mid p] \\
& +\beta^{s}\left\{G\left(q_{s}^{*}(p) \mid p\right) V_{s}\right. \\
& \left.+\left(1-\beta^{s}\right)^{-1} \int_{q_{s}^{*}(p)}^{\infty}\{b(s)[u(q)-p]-r\} g(q \mid p) d q\right\} .
\end{aligned}
$$

Comment 1: Assuming $U(p, q)$ is defined as in (20), an increase in $s$ has two effects when $r>0$; since repurchase is postponed into the future the cost of observing a low value of $Q$ is increased, but at the same time the repurchase cost, $r$, is paid less often. When $r=0$, then for any $s \geqslant 1, V_{s}>V_{s+1}$. For large $r$, though, $V_{s}<V_{s+1}$. In fact, it can be proven formally that for any $s \geqslant 1$ there exists $r^{*}(s)>0$, such that $r<r^{*}(s)$ implies $V_{s}>V_{s+1}, r=r^{*}(s)$ implies $V_{s}=V_{s+1}$, and $r>r^{*}(s)$ implies $V_{s}<V_{s+1}$.

While Comment 1 is not trivial to prove, it is quite intuitive. The more interesting results concern $\xi_{s}$ and $q_{s}^{*}(p) .^{11}$

Theorem 3: Suppose $V_{s}\left(1-\beta^{s}\right)<V_{s+1}\left(1-\beta^{s+1}\right)$ for some $s \geqslant 1$. Then $(i)$ $q_{s}^{*}(p)<q_{s+1}^{*}(p)$ for all $p \in[0, \bar{p}]$ and (ii) $\xi_{s} \geqslant \xi_{s+1}$ with strict inequality if $\xi_{s+1}<\bar{p}$.

Proof: Using the definition of $q_{s}^{*}\left(\xi_{s}\right)$ and the fact that $V_{s}=B_{s}\left(\xi_{s}\right)$, one can derive the following condition in $q_{s}^{*}\left(\xi_{s}\right)$ after integrating $B_{s}\left(\xi_{s}\right)$ by parts:

$$
\begin{aligned}
0= & \left(1-\beta^{s}\right) E\left[u(Q) \mid \xi_{s}\right]-u\left(q_{s}^{*}\left(\xi_{s}\right)\right)+(1-\beta) r \\
& +\beta^{s}\left\{\lim _{q \rightarrow \infty} u(q)-\int_{q_{s}^{*}\left(\xi_{s}\right)}^{\infty} u^{\prime}(q) G\left(q \mid \xi_{s}\right) d q\right\} .
\end{aligned}
$$

Now suppose that $\xi_{s}<\xi_{s+1}$. Then using (23) it can be shown that $q_{s}^{*}\left(\xi_{s}\right)>$ $q_{s+1}^{*}\left(\xi_{s+1}\right)$. But $d q_{s}^{*}(p) / d p>0$ for all $s$. Moreover, $V_{s}\left(1-\beta^{s}\right)<V_{s+1}\left(1-\beta^{s+1}\right)$

\footnotetext{
${ }^{10}$ There is an obvious problem with simply assuming $U(p, q)$ is received over $s+1$ periods instead of $s$ periods $-V_{s}>V_{s+1}$ would generally hold due simply to the decrease in the per-period utility associated with increased durability. The special form of $U(p, q)$ used in this section eliminates this "confounding" effect.

${ }^{11}$ It would be useful to know the relationship between $r^{*}(s)$ and $c$. Since it is natural to assume $c \geqslant r$, the condition $r^{*}(s)>c$ would imply that $V_{s}>V_{s+1}$ for all feasible $r$. However, I have not been able to establish any precise results in this regard.
} 
implies $q_{s+1}^{*}(p)>q_{s}^{*}(p)$ by definition. Hence it must be that $\xi_{s} \geqslant \xi_{s+1}$ (see Figure $1)$, contradicting the assumption that $\xi_{s}<\xi_{s+1}$.

Q.E.D.

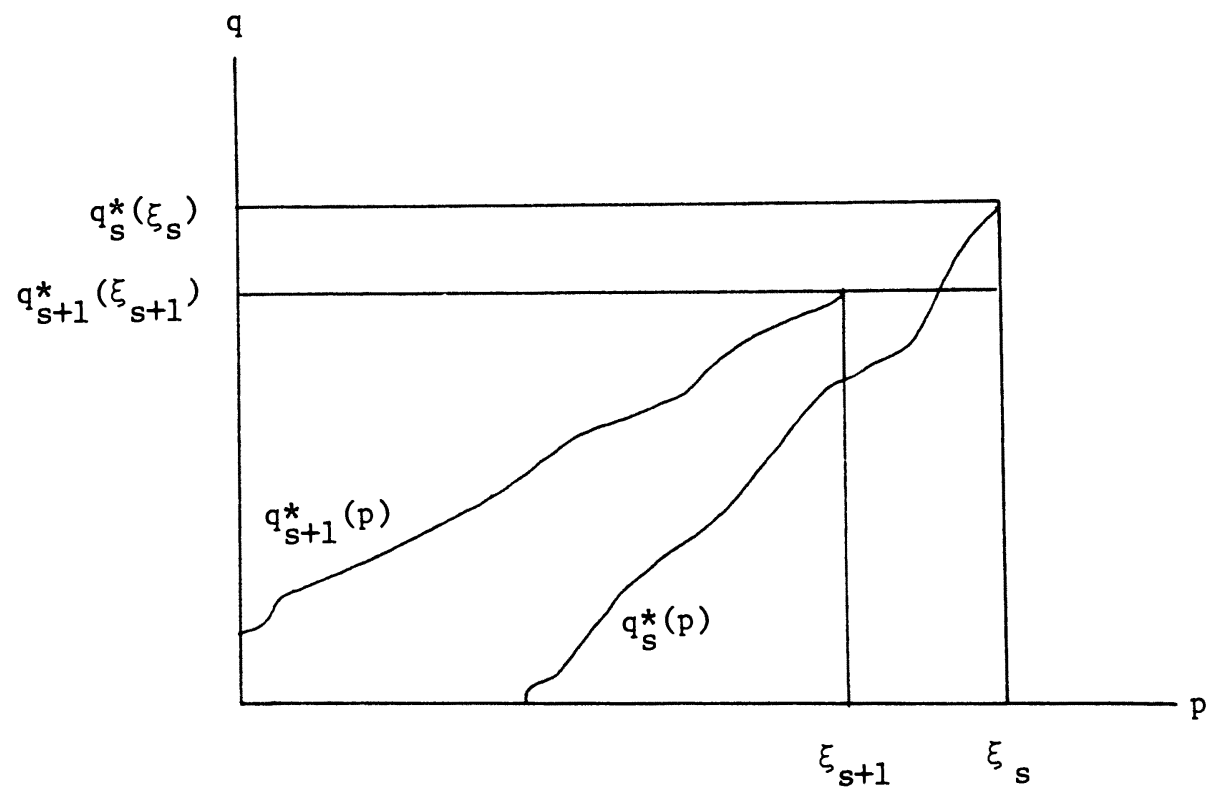

FIGURE 1-Form of $q_{s}^{*}(p)$ and $q_{s+1}^{*}(p)$.

THEOREM 4: Suppose $V_{s}\left(1-\beta^{s}\right)>V_{s+1}\left(1-\beta^{s+1}\right)$ for some $s \geqslant 1$. Then $(i)$ $q_{s}^{*}(p)>q_{s+1}^{*}(p)$ for all $p \in[0, \bar{p}]$ and (ii) $\xi_{s} \geqslant \xi_{s+1}$ with strict inequality if $\xi_{s+1}<\bar{p}$.

The proof of Theorem 4 requires the following lemma.

Lemma 3: Suppose $V_{s}\left(1-\beta^{s}\right)>V_{s+1}\left(1-\beta^{s+1}\right)$ for some $s \geqslant 1$. Then $d B_{s}(p) / d p$ is negative and decreasing in $s$.

Proof of Lemma 3: From (11) we have

$$
\frac{d B_{s}(p)}{d p}=-\int_{\bar{w}(p)}^{\bar{w}(p)} \frac{\partial \psi(w \mid p)}{\partial p} d w-\beta^{s}\left(1-\beta^{s}\right)^{-1} \int_{V_{s}\left(1-\beta^{s}\right)+r}^{\bar{w}(p)} \frac{\partial \psi(w \mid p)}{\partial p} d w .
$$

Now $\partial \psi(w \mid p) / \partial p>0$ so that $d B_{s}(p) / d p<0$. But as $s$ rises, $V_{s}\left(1-\beta^{s}\right)$ falls, implying $d B_{s}(p) / d p$ falls as $s$ rises. Q.E.D.

Proof of TheOREM 4: With $V_{s}\left(1-\beta^{s}\right)>V_{s+1}\left(1-\beta^{s+1}\right)$, then by definition $q_{s}^{*}(p)>q_{s+1}^{*}(p)$. Consider part (ii), and assume $\xi_{s}<\xi_{s+1}$. In this case Figure 2 
illustrates $B_{s}(p)$ and $B_{s+1}(p)$. Clearly when Lemma 3 holds $B_{s}(p)-B_{s+1}(p)<$ $V_{s}-V_{s+1}$ for $p \leqslant \xi_{s+1}$. Thus $B_{s}(p)-V_{s}<B_{s+1}(p)-V_{s+1}$ for all $p \leqslant \xi_{s+1}$. As in equation (4),

$$
c=\int_{0}^{\xi_{s}}\left[B_{s}(p)-V_{s}\right] f(p) d p
$$

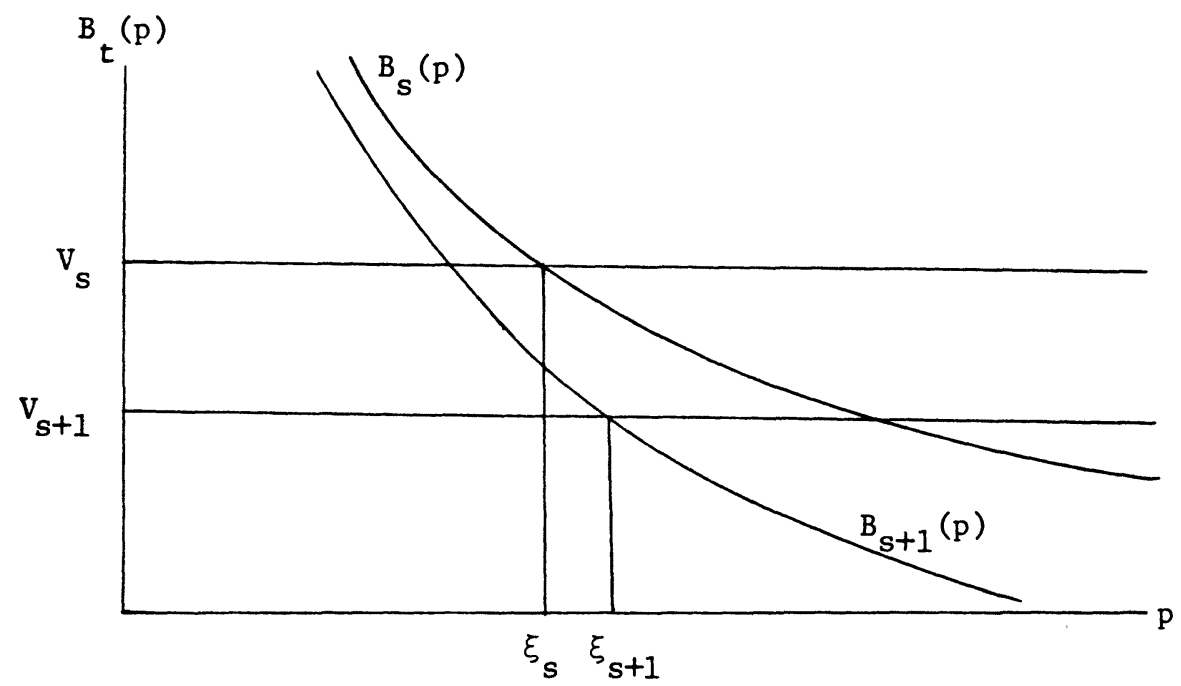

FIGURE 2.-Proof of Theorem 4.

Consider (24) when durability is $s+1$; $\xi_{s}$ rises as does $B_{s}(p)-V_{s}$. But $B_{s}(p)-$ $V_{s} \geqslant 0$ on $\left[0, \xi_{s}\right]$. Hence $\xi_{s}<\xi_{s+1}$ leads to a contradiction and it must be that $\xi_{s} \leqslant \xi_{s+1}$.

Q.E.D.

Theorems 3 and 4 establish that regardless of whether a price-compensated increase in durability is beneficial overall (in the sense of increasing $V_{s}$ ), an increase in $s$ always causes the reservation price to fall. That is, a pricecompensated increase in durability always induces more search prior to the purchase of a good.

With respect to evaluation, Theorem 3 is ambiguous but Theorem 4 shows that if repurchase costs are low enough then a price-compensated increase in durability reduces the ex ante expected probability of not repurchasing a good, conditional on its price being less than or equal to the reservation price. ${ }^{12}$ Hence if $V_{s}\left(1-\beta^{s}\right)>V_{s+1}\left(1-\beta^{s+1}\right)$, then the price-compensated increase in durability increases search but reduces evaluation. If $V_{s}\left(1-\beta^{s}\right)<V_{s+1}\left(1-\beta^{s+1}\right)$ then search still increases, but evaluation might increase as well. 
These results are counter to Nelson's assertion that there will be "larger sample sizes for search for nondurable goods than for search for durable goods" [6, $p$. 318]. However, this can be partially explained by the restriction of Theorems 3 and 4 to price-compensated increases in durability. For example, the theorems should not be interpreted as implying there will be more search for toaster ovens than lettuce because toaster ovens have longer lifetimes. They do imply that if a new variety of lettuce appears on the market which when compared to the current market variety (a) yields twice as many salads, (b) keeps twice as long in the refrigerator, and (c) costs twice as much (on average), then we would expect more search for the new variety than the current variety.

\section{CONCLUSION}

This paper has shown that a number of interesting results can be obtained by incorporating the distinction between search characteristics and experience characteristics into a formal search model, but at this level of generality, further results are difficult (if not impossible) to obtain. It would be interesting to know how changes in the distribution of price and quality effect an optimal search strategy. Even if one assumes (a) utility is linear and (b) price and quality are distributed independently, it is difficult to ascertain the effects on reservation prices and reservation qualities of mean-preserving spreads in either distribution. However, by making additional assumptions (especially regarding the distribution of quality) Lippman and McCall [3] have recently been able to establish some results along these lines.

Other interesting extensions of the model can be obtained by relaxing various other assumptions. For example, one could allow quality to be observed prior to purchase at some finite cost. As noted in the introduction, this is essentially the kind of problem analyzed by MacQueen [4], although he did not allow for repurchase. It might also be possible to relax the assumption (stated in footnote 5) that it never pays to throw away (or sell) a poor quality good and initiate a new round of inspection prior to the end of the good's lifetime.

\section{California Institute of Technology}

Manuscript received August, 1977; revision received August, 1979.

\section{REFERENCES}

[1] Hirshleifer, J.: "Where Are We in the Theory of Information," American Economic Review, 63 (1973), 31-39.

[2] KoHN, M., AND S. SHAVELl: "The Theory of Search," Journal of Economic Theory, 9(1974), 93-123.

[3] LippMAN, S., AND J. J. MCCALl: "The Economics of Belated Information," unpublished manuscript, University of California at Los Angeles, 1978.

[4] MacQueen, J. B.: "Optimal Policies for a Class of Search and Evaluation Problems," Management Science, 10 (1964), 746-79. 
[5] MacQueen, J. B., ANd R. G. Miller, Jr.: "Optimal Persistence Policies," Operations Research, 8 (1960), 362-380.

[6] Nelson, P.: "Information and Consumer Behavior," Journal of Political Economy, 78 (1970), 311-329.

[7] Pencavel, J.: "Wages, Specific Training, and Labor Turnover in U.S. Manufacturing Industries," International Economic Review, 13 (1972), 53-64.

[8] STIGlitz, J.: "The Theory of Screening, Education, and the Distribution of Income," American Economic Review, 65 (1975), 283-300.

[9] ReYNOLDS, L.: The Structure of Labor Markets. New York: Harper, 1951.

[10] WildE, L.: "An Information-Theoretic Approach to Job Quits," in Studies in the Economics of Search, ed. by S. Lippman and J. J. McCall. Amsterdam: North-Holland, 1979. 
http://www.jstor.org

\title{
LINKED CITATIONS
}

\author{
- Page 1 of 2 -
}

You have printed the following article:

On the Formal Theory of Inspection and Evaluation in Product Markets

Louis L. Wilde

Econometrica, Vol. 48, No. 5. (Jul., 1980), pp. 1265-1279.

Stable URL:

http://links.jstor.org/sici?sici=0012-9682\%28198007\%2948\%3A5\%3C1265\%3AOTFTOI\%3E2.0.CO\%3B2-K

This article references the following linked citations. If you are trying to access articles from an off-campus location, you may be required to first logon via your library web site to access JSTOR. Please visit your library's website or contact a librarian to learn about options for remote access to JSTOR.

\section{[Footnotes]}

\author{
${ }^{6}$ Optimal Persistence Policies \\ J. MacQueen; R. G. Miller Jr. \\ Operations Research, Vol. 8, No. 3. (May - Jun., 1960), pp. 362-380. \\ Stable URL: \\ http://links.jstor.org/sici?sici=0030-364X\%28196005\%2F06\%298\%3A3\%3C362\%3AOPP\%3E2.0.CO\%3B2-L
}

\section{References}

\author{
${ }^{1}$ Where Are We in the Theory of Information? \\ J. Hirshleifer \\ The American Economic Review, Vol. 63, No. 2, Papers and Proceedings of the Eighty-fifth Annual \\ Meeting of the American Economic Association. (May, 1973), pp. 31-39. \\ Stable URL: \\ http://links.jstor.org/sici?sici=0002-8282\%28197305\%2963\%3A2\%3C31\%3AWAWITT\%3E2.0.CO\%3B2-V
}

\section{${ }^{4}$ Optimal Policies for a Class of Search and Evaluation Problems}

James B. MacQueen

Management Science, Vol. 10, No. 4. (Jul., 1964), pp. 746-759.

Stable URL:

http://links.jstor.org/sici?sici=0025-1909\%28196407\%2910\%3A4\%3C746\%3AOPFACO\%3E2.0.CO\%3B2-Y

NOTE: The reference numbering from the original has been maintained in this citation list. 
http://www.jstor.org

\section{LINKED CITATIONS \\ - Page 2 of 2 -}

\section{${ }^{5}$ Optimal Persistence Policies}

J. MacQueen; R. G. Miller Jr.

Operations Research, Vol. 8, No. 3. (May - Jun., 1960), pp. 362-380.

Stable URL:

http://links.jstor.org/sici?sici=0030-364X\%28196005\%2F06\%298\%3A3\%3C362\%3AOPP\%3E2.0.CO\%3B2-L

\section{${ }^{6}$ Information and Consumer Behavior}

Phillip Nelson

The Journal of Political Economy, Vol. 78, No. 2. (Mar. - Apr., 1970), pp. 311-329.

Stable URL:

http://links.jstor.org/sici?sici=0022-3808\%28197003\%2F04\%2978\%3A2\%3C311\%3AIACB\%3E2.0.CO\%3B2-G

\footnotetext{
${ }^{7}$ Wages, Specific Training, and Labor Turnover in U.S. Manufacturing Industries John H. Pencavel

International Economic Review, Vol. 13, No. 1. (Feb., 1972), pp. 53-64.

Stable URL:

http://links.jstor.org/sici?sici=0020-6598\%28197202\%2913\%3A1\%3C53\%3AWSTALT\%3E2.0.CO\%3B2-N

${ }^{8}$ The Theory of "Screening," Education, and the Distribution of Income Joseph E. Stiglitz

The American Economic Review, Vol. 65, No. 3. (Jun., 1975), pp. 283-300.

Stable URL:

http://links.jstor.org/sici?sici=0002-8282\%28197506\%2965\%3A3\%3C283\%3ATTO\%22EA\%3E2.0.CO\%3B2-0
}

NOTE: The reference numbering from the original has been maintained in this citation list. 